Vol. 1 | No. 3 | Juli 2020 | Hal. 212 - 217

\title{
PENERAPAN HASIL SOSIALISASI UNTUK MENGATASI KENAKALAN REMAJA DALAM KEHIDUPAN BERMASYARAKAT
}

\author{
Artono Raharjo', Indrawan', Fadhlan Pandu Rabbani' ${ }^{2}$, Siti Nur Amanah ${ }^{3}$, Donny \\ Pangestu ${ }^{4}$, Adib Lazward Irkhami4 ${ }^{4}$ Kurnia Purnama Sumsa5, Pandu Dzaky Islam4, \\ Rafli Razak', Vika Mu'izul Islam ${ }^{3}$, Laila Mar'atus Sholihah ${ }^{3}$, Tantri Wahyuni ${ }^{6}$, Alifia \\ Nuraini $^{4}$, Rakhmad Tisno Febriyanto ${ }^{5}$ \\ ${ }^{1}$ Fakultas Teknik, Universitas Islam Malang \\ ${ }^{2}$ Fakultas Peternakan, Universitas Islam Malang \\ ${ }^{3}$ Fakultas Agama Islam, Universitas Islam Malang \\ ${ }^{4}$ Fakultas Ekonomi dan Bisnis, Universitas Islam Malang \\ ${ }^{5}$ Fakultas Hukum, Universitas Islam Malang \\ ${ }^{6}$ Fakultas Keguruan dan Ilmu Pendidikan, Universitas Islam Malang
}

Korespondensi email: artonor@unisma.ac.id

\begin{abstract}
ABSTRAK
Narkoba, Sex Education, dan Bullying saat ini sedang tidak asing lagi dikalangan remaja millenial. Masalah pergaulan bebas yang semakin marak dikalangan remaja membuat semakin menipisnya generasi penerus bangsa saat ini. Penyalah gunaan narkoba saat ini pengedaran tidak hanya dilakukan orang dewasa akan tetapi dalam hal ini sudah merajalela dikalangan siswa/i bahkan anak sekolah dasar. Sex education sudah merajalela dengan adanya teknologi yang semakin berkembang sehingga dapat dengan mudah mengakses apa yang diinginkan, dampaknya yaitu semakin banyak pernikahan dini. dan bullying disekolah yang semakin marak membuat mental para remaja menurun. Melalui lembaga pengabdian ini untuk membantu para remaja khususnya siswa/i untuk menambah pengetahuan ilmu melalui pengadaan sosialisasi mengenail bahaya Narkoba, Sex Bebas, dan Bullying. Kegiatan ini dilakukan di Aula SMKN 1 Ampelgading. Sosialisasi ini sangat bermanfaat bagi siswa/i untuk menambah wawasan tentang bahaya pergaulan bebas. Dan faktor yang berperan penting adalah Teknologi Informasi.
\end{abstract}

Kata Kunci: narkoba; sex education; bullying; teknologi informasi.

\section{PENDAHULUAN}

Masa remaja merupakan masa yang dapat disebut sebagai masa perubahan antara lain perubahan dalam sikap, ataupun perubahan dalam fisik (Pramesti, Trisnadewi, \& Idayani, 2019; Suryani, Rafiyah, Mardiah, \& Sutini, 2014). Remaja dalam tahap ini mengalami banyak perubahan seperti halnya tahap emosi, tubuh, minta, pola perilaku, dan penuh dengan perilaku atupun masalah pada masa remaja (Gunarsa \& Gunarsa, 2008; Jannah, 2017; Aulia, 2014). Masa remaja yaitu masa dimana mereka masih mencari pola hidup terkadang mereka membuat kesalahan dengan cra mencoba-coba hal yang baru tanpa memikirkan hal tersebut mempunyai dampak bahaya atau tidak bagi mereka (Prasasti, 2017). Kesalahan tersebut akan menjadi dampak kekawatiran bagi orang disekitarnya maupun lingkungannya. 
Remaja juga merupakan aset suatu bangsa yang menggembirakan disisi lain dengan adanya pembinaan yang diadakan organisasi akhir-akhir ini. Disisi lain semakin banyak penurunan moral yang semakin banyak menimpa di kalangan remaja. Hal yang melatar belakangi dampak kenakalan remaja yaitu dengan kurangnya kontrol diri yang semakin lemah. Kenakalan remaja dapat ditinjau dari beberapa faktor yaitu faktor internal dan eksternal salah satu faktor internalnya yaitu berkurangnya kontrol diri yang semakin lemah. Sedangkan faktor eksternalnya yaitu kurangnya pantauan dari orang tua, meniru budaya kebarat-barat an, pengaruh teman sebaya, dan kurang nya mengenali agama beserta tempat Pendidikan (Mumtahanah, 2015; Sumara, Humaedi, \& Santoso, 2017).

Narkoba dan pergaulan bebas sudah tidak asing lagi dikalangan remaja. Maka dari itu melalui kegiatan pengabdian masyarakat kami membantu generasi millenial untuk lebih waspada dengan kenakalan remaja melalui pengadaan sosialisasi mengenai bahaya narkoba, sex education, dan bullying. Bahaya narkoba yang berdampak pada generasi penerus bangsa, sex education yang berdampak pada semakin berkembag pesatnya pernikahan dini, dan dampak bullying di sekolah membuat gangguan mental bagi korban pelaku bullying (Arianty, 2016).

Dari pemaparan latar belakang diatas maka penulis mengambil rumusan masalah 1. Apakah dengan adanya sosialisasi bahaya narkoba, sex education, dan bullying siswa/i dapat menambah pengetahuan mereka? Tujuan sosialisasi ini yaitu untuk meningkatkan pengetahuan siswa atau siswi tingkat SLTP dan SLTA agar lebih waspada terhadap penyakit HIV/AIDS, menjauhi tindakan bullying di sekolah dan bahaya penyalahgunaan narkoba.

Untuk kontribusi penelitian bagi pihak sekolah yaitu diharapkan dengan adanya sosialisasi ini siswa/i dapat mampu mengantisipasi dirinya sendiri untuk lebih berhati-hati dalam memilih pergaulan. Dan kontribusi praktis bagi penyelenggara sosialisasi yaitu menambah pengetahuan bagi siswa/siswi agar lebih waspada terhadap pergaulan bebas yang sedang marak saat ini.

\section{Narkoba}

Menurut Eleanora (2011) narkoba adalah sesuatu yang menidurkan dan membiuskan sedangkan narkotika berarti membiuskan sehingga seseorang yang mengkonsumsi tidak merasakan apa-apa atau tidak sadar diri. Menurut UU No. 22/1997 narkotika adalah tanaman papever, opium mentah, opium masak, seperti candu, jicing, jocingko, opium obat, morfina, tanaman koka, daun koka, kokaina mentah, ekgonina, tanaman ganja, damar ganja, garam-garam atau turunannya dari morfina atau kokaina.

Disimpulkan bahwa narkotika yaitu obat ataupun zat yang dapat menenangkat syaraf dan membuat orang kehilangan kesadaran, penghilang rasa nyeri ataupun sakit, serta dapat membuat orang mengkonsumsi kecanduan yang ditetapkan menteri kesehatan sebagai narkotika (Phahlevy \& Maghfiroh, 2019). Pada akhir 2014 perkiraan penyalahgunaan narkoba menurut hasil survey BNN yaitu dapat dikirakan sebanyak 3,8 juta sampai 4,1 juta orang yang pernah menggunakan narkoba dalam kurun waktu setahun terakhir. Dikelompokkan pada usia 10-59 tahun pada 2014, ada sekitar 1 dari 44 sampai 48 yang berusia 10-59 tahun yang pernah mengkonsumsi narkoba pada tahun 2014.

\section{Sex Education}

Menurut Rohmaniyah (2018) seksualitas berasal dari kata sex dari biologi yang berarti pembedaan antara laki-laki dan perempuan. Namun makna seksualitas bada abad ke-18 yaitu diartikan sebagai kontruksi tentang norma dan pengetahuan serta perilaku yang subyektif mengenai sex yang terkait dengan kekuasaan pengetahuan. (Pakasi \& Kartikawati, 2013) menyatakan bahwa sex merupakan suatu aspek terpenting 
dalam kesehatan dan kebahasiaan untuk manusia. Seksualitas juga dipengaruhi oleh interaksi intiologis, psikologis, sosial, serta ekonomi. Namun sangat banyak aspek lainnya akan tetapi tidak banyak orang mengetahuinya.

\section{Bullying}

Menurut buku yang ditulis oleh Wibowo (2019) yang berjudul Penerapan Hukum Pidana Dalam Penanganan Bullying di Sekolah mengartikan Bullying atau disebut dengan intimidasi adalah suatu tindakan agresif yang dilakukan seseorang kepada orang lain yang menyebabkan orang lain atau korban tersebut mengalami luka atau ketidaknyamanan. Para pelaku tindakan bullying membuat para lawan ataupun korban dengan tindakan ataupun kontak fisik sesuai dengan kesenangan para pelaku demi untuk mencapai tujuannya. Sedangkan adapun unsur-unsur bullying seperti adanya tindakan pelaku agresif terhadap lawannya, perlakuan agresif tersebut berakibat orang lain terluka, dan perlakuan agresif tersebut berupa kontak fisik, kata-kata kotor maupun tindakan langsung terhadap korban.

\section{METODE}

Mahasiswa KKN PPM sebagai fasilitator dalam kegiatan. Sesuai dengan program kegiatan dari program Manajemen, Ilmu Hukum, Teknik Sipil, Peternakan, Pendidian Agama Isam, adapun metode yang digunakan adalah (1) berbasis kelompok yaitu kelompok sebagai media perencanaan kegiatan serta pendampingan bersama dalam kegiatan. (2) berbasis penelitian ketrampilan artinya para kelompok dilatih untuk dapat menguasai ketrampilan yang sudah dilatihkan.

Dalam kegiatan KKN PPM Tematik yang bertema Lembaga Pemerintahan maka pelaksana mengadakan sosialisasi kenakalan remaja seperti penyalah gunaan narkoba, bahaya HIV/AIDS, dan mencegah bullying di sekolah. Dilaksanakan pada siswa-siswi tingkat SLTP dan SLTA di Kecamatan Ampelgading Kabupaten Malang. Dalam hal ini kami mengundang delegasi 5 orang dalam setiap sekolah tingkat SLTP dan SLTA yang ada di Kecamatan Ampelgading. Acara sosialisasi dilaksanakan di Aula SMK 1 Ampelgading.

Metode yang digunakan adalah pre-test, ceramah, diskusi, demostrasi, dan post test. Materi yang diberikan merupakan bahaya penyalahgunaan narkoba beserta, serta dampak dari sex bebas dan bullying di sekolah. Media yang digunakan berupa powerpoint, serta film dampak nakoba beserta bahaya sex bebas.

Pemutaran film tentang narkoba bertujuan untuk mengenali jenis narkoba dan tubuhan ganja agar siswa atau siswi dapat lebih mengetahui dan mengatisipasi terhadap diri senidiri. Dan pemaparan film tentang sex bebas mengantisipasi bahwa melihat pornografi berdampak kecanduan dan kerusakan otak. Berawal dari melihat pornografi yang memnyebabkan kerusakan dari limbig sehingga beredar kasus seksualitas yang sudah tidak asing lagi dikalang siswa ataupun siswi tingkat SLTP dan SLTA yang berdampak HIV/AIDS.

\section{HASIL DAN PEMBAHASAN}

Dalam sosialisasi ini diadakan di Aula SMKN 1 Ampelgading pada hari Rabu, 19 Februari 2020 dengan tema "Jaga Dirimu, Rangkul Kawanmu" dalam acara ini mahasiswa pengabdian masyarakat bekerja sama dengan instansi pemerintah yaitu dari polsek Ampelgading, pihak pukesmas, dan rekan mahasiswa yang menjadi korban Bullying. Dalam sosialisasi ini pihak polsek Ampelgading menjelaskan bahaya narkoba dan jenis-jenis narkoba beserta ciri-ciri orang yang sudah kecanduan narkoba.

Sedangkan pada instansi pemerintah kami bekerja sama dengan pihak pukesmas. menjelaskan tentang dampak pergaulan bebas pada masa remaja dan mengenali 
pengetahuan tentang penyakit HIV/AIDS. Edukasi seksualitas bagi ditemukan pada masa remaja saat ini, mereka ada yang mengetahui seksualitas dan ada juga yang belum mengetahui. Masih banyak juga remaja yang melakukan hal tersebut meskipun mereka belum cukup umur. Penyebab dari remaja melakukan hal tersebut yaitu salah satunya dampak teknologi yang semakin canggih, sehingga para remaja pada saat ini mudah untuk mengakses apapun yang mereka inginkan.

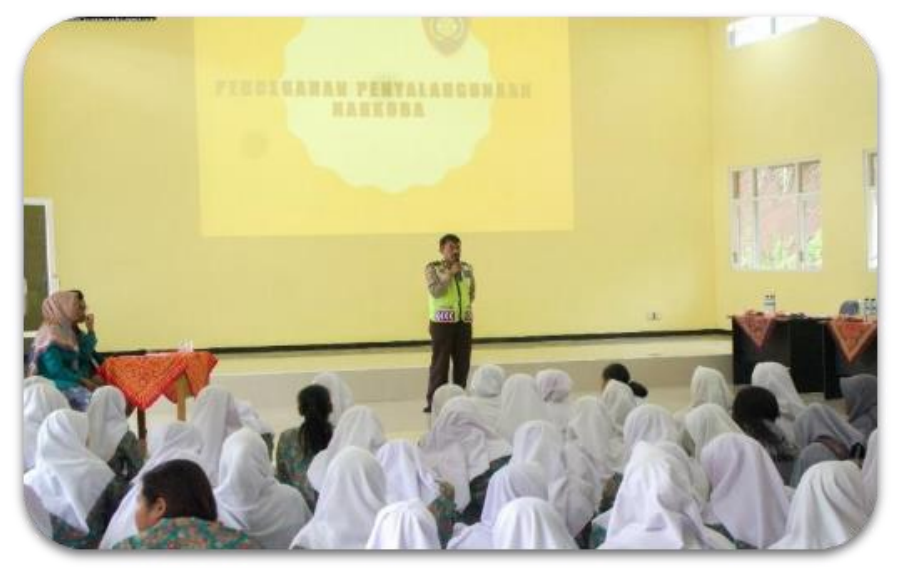

Gambar 1. Pemaparan materi tentang penyalahgunaan narkoba dari pihak kapolsek Ampelgading

Bahaya bullying di sekolah, dalam sosisalisasi ini masasiswa pengabdian masyarakat mengambil narasumber dari anggota mahasiswa pengabdian sendiri yang menjadi korban Bullying di sekolah. Narasmber menceritakan pengalaman nya waktu di bully rekannya dan memberikan tips atau penanggulangan untuk menyikapi bullying tersebut.

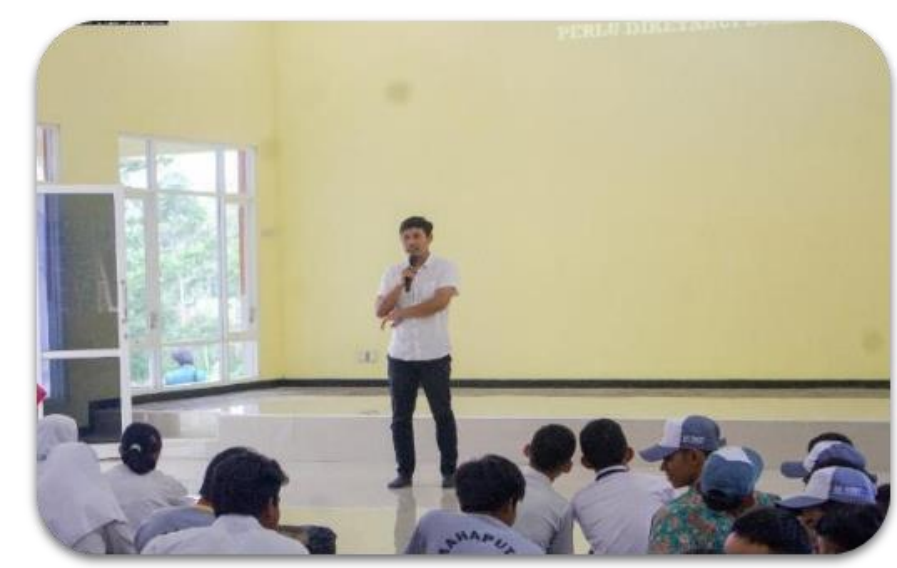

Gambar 2. Pemaparan mengenai hubungan sex bebas dan penyakit HIV/AIDS oleh staf dokter Puskesmas Ampelgading

Dalam kegiatan yang diadakan mahasiswa pengabdian ini memberikan edukasi ataupun sasaran terhadap siswa atau siswi tingkat SLTP dan SLTA di Kecamatan Ampelgading untuk memberikan ilmu tentang pencegahan penyakit HIV/AIDS, bahaya penyalahgunaan narkoba, dan bullying di sekolah. Dimana dalam membahas ketiga materi sosialisasi ini sangat berkaitan terhadap para remaja maupun masyarakat sekitar. Penyebab dari ketiga tersebut yang paling dominan yaitu keingintahuan mereka ataupun bisa disebut coba-coba dan faktor emosional yang tidak terkontrol, maka membuat hal itu terjadi. 


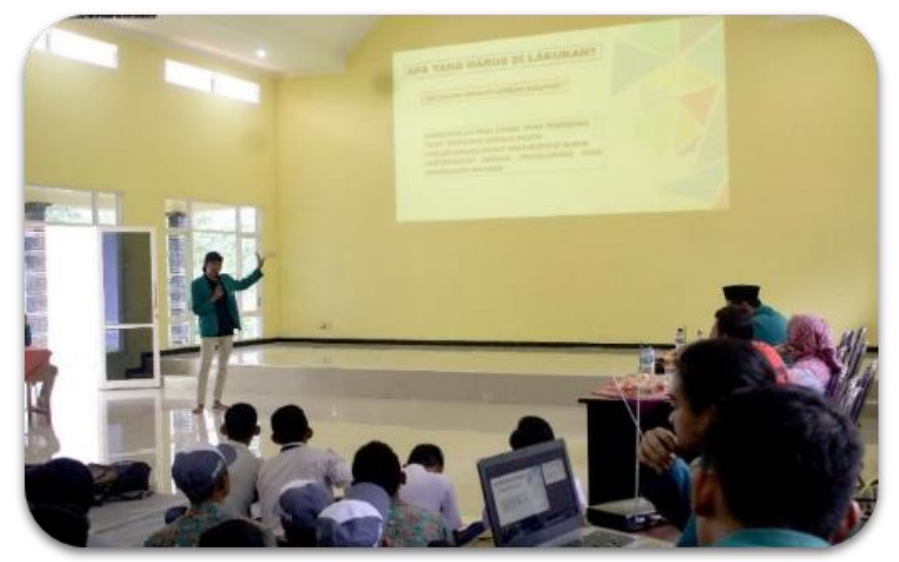

Gambar 3. Pemaparan tentang bullying oleh tim

Dalam acara sosialisasi ini direspon cukup baik terhadap pihak yang hadir dan memberikan umpan balik antara pemateri dan siswa-siswi untuk bertanya jawab seputar materi yang telah disampaikan. Dengan hal ini memberikan kami hasil yang memuaskan. Dengan acara sosialisasi yang menjadi tujuan program kerja kami yaitu kepedulian terhadap remaja dan masyarakat dalam mempelajari masalah generasi bangsa yang ada di sekitar lingkungan dapat berjalan dengan lancar.

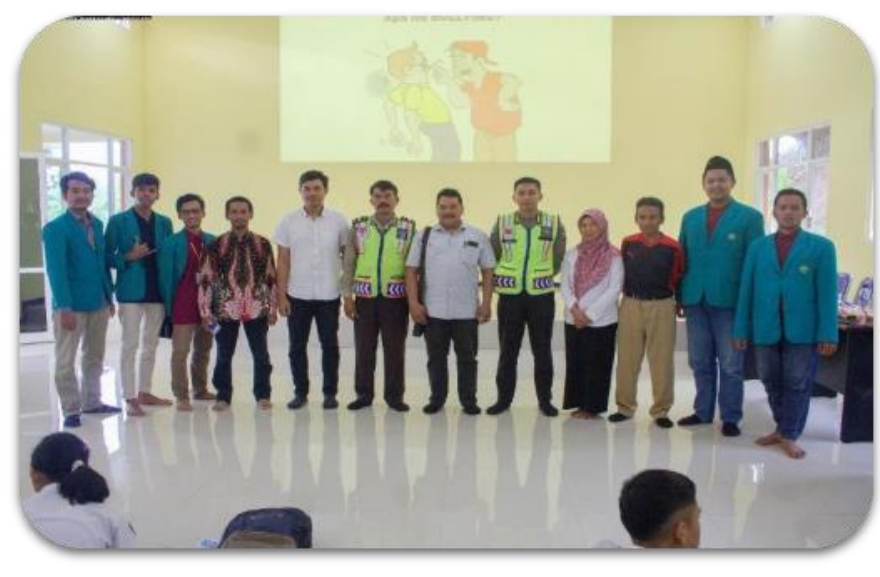

Gambar 4. Foto bersama pasca kegiatan

\section{KESIMPULAN}

Kegiatan sosialisasi mengenai Narkoba, Sex Education, dan Bullying sangat diperlukan bagi siswa/i tingkat SLTP dan SLTA karena sudah menginjak masa remaja yang masih labil dengan rasa ingin tau dengan hal yang baru, terutama dalam hal yang berbau negatif. Kegiatan sosialisasi ini sangat bermanfaat untuk bagi siswa/i untuk mengetahui ilmu pengetahuan tentang bahaya narkoba, sex education, dan bullying yang sedang marak di sekelah-sekolah. Dan salah satu faktor yang sangat berperan dalam hal ini adalah kemajuan teknologi yang semakin canggih sehingga setiap orang bisa mengakses apapun yang mereka inginkan. Misalnya melihat konten-konten negatif yang dengan mudah mempengaruhi masa remaja saat ini untuk ikut serta menirukan.

\section{DAFTAR RUJUKAN}

Arianty, A. E. (2016). Faktor Penyebab Tradisi Bullying di SMA Al Azhar 2 Pejaten Jakarta Selatan. Universitas Islam Negeri Syarif Hidayatullah Jakarta. Retrieved from http://repository.uinjkt.ac.id/dspace/bitstream/123456789/33584/1/ANNISA 
ELFA ARIANTY - FDK.pdf

Aulia, F. (2014). Studi Deskriptif Help Seeking Behaviour Pada Remaja yang Pernah Mengalami Parental Abuse Ditinjau dari Tahap Perkembangan (Masa Awal Anakanak - Masa Remaja) dan Identitas Gender. Calyptra: Jurnal Ilmiah Mahasiswa Universitas Surabaya, 3(1), 1-17. Retrieved from https://journal.ubaya.ac.id/index.php/jimus/article/view/1750

Eleanora, F. N. (2011). Bahaya Penyalahgunaan Narkoba Serta Usaha Pencegahan Dan Penanggulangannya (Suatu Tinjauan Teoritis). Jurnal Hukum, 25(1), 439-452. https://doi.org/10.26532/jh.v25i1.203

Gunarsa, S. D., \& Gunarsa, Y. S. D. (2008). Psikologi Praktis: Anak, Remaja dan Keluarga. (S. B. G. Mulia, Ed.) (8th ed.). Jakarta: PT. BPK Gunung Mulia.

Jannah, M. (2017). Remaja Dan Tugas-Tugas Perkembangannya Dalam Islam. Psikoislamedia : Jurnal Psikologi, 1(1), 243-256. https://doi.org/10.22373/psikoislamedia.v1i1.1493

Mumtahanah, N. (2015). Upaya Menanggulangi Kenakalan Remaja Secara Preventif, Represif, Kuratif dan Rehabilitasi. Al Hikmah Jurnal Studi Keislaman, 5(2), 278-279. https://doi.org/10.36835/hjsk.v5i2.2999

Pakasi, D. T., \& Kartikawati, R. (2013). Antara kebutuhan dan tabu: pendidikan seksualitas dan kesehatan reproduksi bagi remaja di SMA. Jurnal Makara Seri Kesehatan, 17(2), 79-81. https://doi.org/10.7454/msk.v17i2.xxxx

Phahlevy, R. R., \& Maghfiroh. (2019). PERGESERAN KONSEP NARKOTIKA DALAM SISTEM $\begin{array}{llll}\text { HUKUM INDONESIA. RES JUDICATA, 2(2), 259-275. } & \end{array}$ https://doi.org/10.2307/790303

Pramesti, T. A., Trisnadewi, N. W., \& Idayani, S. (2019). Pencegahan penyalahgunaan narkoba dan seks bebas di kalangan remaja millennial. In Seminar Nasional Hasil Penelitian dan Pengabdian Masyarakat Seri ke-3 (pp. 128-134).

Prasasti, S. (2017). Kenakalan remaja dan faktor penyebabnya. In Seminar Nasional Bimbingan dan Konseling (Vol. 1, pp. 28-45). Retrieved from prosiding.unipma.ac.id/index.php/SNBK/article/download/110/109

Rohmaniyah, I. (2018). Konstruksi Seksualitas Dan Relasi Kuasa Dalam Praktik Diskursif Pernikahan Dini. Musãwa Jurnal Studi Gender Dan Islam, 16(1), 33-52. https://doi.org/10.14421/musawa.2017.161.33-52

Sumara, D., Humaedi, S., \& Santoso, M. B. (2017). Kenakalan Remaja Dan Penanganannya. In Prosiding Penelitian dan Pengabdian kepada Masyarakat (Vol. 4, pp. 129-353). Bandung. https://doi.org/10.24198/jppm.v4i2.14393

Suryani, Rafiyah, Mardiah, \& Sutini. (2014). Upaya Pencegahan Penyalahgunaan Narkoba dan Seks Bebas Serta Peningkatan Kemampuan Koping Remaja Berbasis Kelompok Sebaya di SMP DAN SMA di Jatinangor. Dharmakarya: Jurnal Aplikasi Ipteks Untuk Masyarakat, 3(2), 105-108. https://doi.org/10.2134/jeq2004.0288

Wibowo, A. P. S. (2019). Penerapan Hukum Pidana Dalam Penanganan Bullying di Sekolah. (S. F. Manalu, Ed.). Jakarta: Universitas Katolik Indonesia Atma Jaya. Retrieved from https://books.google.co.id/books?hl=en\&lr=\&id=Ed-

kDwAAQBAJ\&oi=fnd\&pg=PA1\&dq=Penerapan + Hukum + Pidana + Dalam + Penangana n+Bullying+di+Sekolah\&ots=uJW_dqZH19\&sig=IrzsApEhRBepYHMcMx2opkeOKM\&redir_esc $=y \# v=$ onepage $\& \mathrm{q}=$ Penerapan Hukum Pidana Dalam Penanganan Bullying di Sekolah\&f=false 